\title{
INTRAPROFESSIONAL CONCERNS
}

JAMES WINTERSTEIN, DC, DACBR ${ }^{a}$

a. President, National University of Health Sciences, Lombard, IL. Submit requests for reprints to: Dr. James Winterstein, President, National University of Health Sciences, 200 E. Roosevelt Rd, Lombard, IL 60148. Paper submitted May 30, 2002.

\section{INTRODUCTION}

Primary care, as it is typically defined by the Institute of Medicine, requires:

1. Accountability - inherent in this is the need to examine and diagnose.

2. Integrated health services - recognition of the value of other providers, ability to work with other providers and awareness of the need to refer to other providers when indicated.

3. Addressing a large majority of personal health-care needs.

4. Accessibility.

5. Sustained partnership with patients.

6. Practice within the context of family and community.

The purpose of this paper will be to look at the profession from the inside with the intention to address the differences of opinion, education and practice as they relate to the various components of primary care.

Of the 6 components just listed, it is my opinion that the first 3 are the areas in which there is the greatest amount of internal conflict regarding how best to address the primary care issue, so I will begin with number one.

\section{DISCUSSION}

\section{Accountability}

In 1907, Shegataro Morikubo, D.C. was arrested for practicing medicine without a license in LaCross Wisconsin. His lawyer, Thomas Morris, made the case that Dr. Morikubo could not be held to the medical statutes because he did not practice medicine. Morris stated, "unlike osteopathy's concern for circulation of the blood, the chiropractor is primarily concerned with nerve impulses, emanating from the brain to control all body functions; the brain, not the blood, is the builder of the body." He also established that the chiropractic "thrust" was different than that of the osteopath (1).

Sometime between 1906 and 1910, B.J. Palmer, D.C. wrote "A chiropractor does not diagnose disease. A chiropractor pays but little attention to symptoms, considering them only as guides showing the location of the causes ... From now on let us use the term 'analyze' instead of 'diagnose,' in connection with disease" (2).

By comparison, John Fitz Alan Howard, D.C. founder of National School of Chiropractic wrote: "In correct diagnosis lies the nucleus of success in the healing art. To begin with, our diagnosis must be thorough and painstaking. No point is of too little importance to be considered....too much emphasis cannot be laid on this point" (3).

This began a 92-year history of disagreement within the chiropractic profession that remains to this day. The crux of the issue of whether or not to diagnose resides in the underlying dogma of the early 20th century which proposed that since chiropractors do not practice medicine, and do not treat disease, there is no need to diagnose. To diagnose, would, in fact, be counterproductive to good chiropractic practice, which is to analyze, locate and correct vertebral subluxations which were believed to interfere with the normal transmission of "mental impulses" from brain cell to tissue cell.

So ingrained is this so-called "philosophy," that even today, a significant number of chiropractors teach and practice this dogma - diagnosis is not necessary in chiropractic practice (4). Perhaps nowhere has this been more evident than in the many disputes of the Council on Chiropractic Education (CCE) over the past decade and a half relating to specific language in the Standards for accreditation. The schools that still believe and teach the old dogma consistently and repeatedly took a stand against the specific language in the Standards which requires the student to "develop a diagnosis." Instead, the suggestion was that we should require a "diagnostic impression," or even better, a "clinical impression," or most appropriately, a "chiropractic analysis." As one who sat for many years on the Board of Directors, I can attest to this reality.

Over the years, and I believe largely because of accreditation standards, the more dogma-oriented schools have 
moved away from the non-diagnosis extreme to a more reasonable position, but they still resist the inclusion of diagnosis as a component of the Standards. One institution clearly continues to disagree with the concept of diagnosis (Sherman) and contends that their only purpose is to teach students how to locate and correct vertebral subluxations, which they teach are detrimental to human health. (Koch D. Personal communciation)

At present, then, within the profession, there are essentially 3 groups that take opposing positions with regard to diagnostic accountability.

1. Those that support the education of our students and the practice of full diagnostic procedures within the scope of the relevant state statutes.

2. Those who teach diagnosis and practice it to a limited degree because of the imposition of accrediting standards, or state statutes.

3. Those who continue to teach an antidiagnostic position and refuse to engage in examination and diagnosis in the practice setting, often using supposed waivers of responsibility with their patients.

Accountability extends to other aspects of chiropractic practice, education, research, politics and legislative intent.

Within the aspect of accountability lies the profession's response to professional standards or guidelines. It became painfully evident that the component of the profession which I shall call the narrow-scope schools and practitioners, all of whom were represented by the Mercy Conference and who participated in the process, would not live with the guidelines almost immediately after the fact. It was within weeks that Dr. Sid Williams came out forcefully against the "Mercy Guidelines," and others soon followed suit.

Within a year following the publication of the Mercy Guidelines, new sets of so-called guidelines were developed that essentially supported the practice of those who refer to themselves as "subluxation based." One need only read those guidelines, whether from the World Chiropractic Alliance or the International Chiropractor's Association, to recognize that they were designed to allow all procedures usually used by the "straight chiropractors" while denying any procedures outside of their narrow scope of vision.

Another aspect of accountability resides in the expected recognition for support of professional practice activities through the application of currently accepted epistemo- logic methods-namely the application of the scientific method to the practice of chiropractic medicine and to the development of new knowledge. In the profession today, there are those-primarily from the broad-scope members-who strongly promote the application of science to practice methods and to the development of new knowledge. On the other hand, there are those, supported primarily by the "straights," who take the position that "biomedical science" and the methods used in controlled studies are not applicable to chiropractic practice. One often hears science denigrated as being too "Newtonian," while the "new thinkers" subscribe to "quantum science" as the pathway to validating what straight chiropractors do. The practical application of this kind of thinking seems to be remarkably absent, however.

An additional component of accountability is the recognition of the need for the practice of evidence-based medicine. Again, there is a clear disparity of position in relation to this component of accountability, with a significant majority taking the position that an authoritarian epistemology is adequate as evidence of what they do, while others have worked hard to embrace a scientific epistemology.

Accountability extends into many areas of professional conduct (for example the undermining of majority legislative intent by minority groups within the profession) and societal expectations, but for purposes of this paper, I shall let the above examples suffice.

\section{Integrated Practice (Integration of Health Services)}

Again because of the old dogma that chiropractors are completely and totally different from allopaths and the practice of chiropractic is unique and separate from any other form of health care, the position taken by these members of the profession is that there cannot be real integration which is, on its face, counterproductive to good chiropractic practice.

One frequently hears these people make the statement that anyone seeking integration with allopaths is really simply a frustrated M.D. or is trying to curry favor with the allopathic community rather than standing up for "real chiropractic," which is the location and correction of subluxations. Thus, the concept of integration is ridiculed by these practitioners and many of the practices of the allopaths are also ridiculed.

Some of the more well known dogmatists within this group teach that vaccination, for example, is unscien- 
tific and therefore, should be discouraged among chiropractic patients. It is further their contention that since human vitalism is diminished by vertebral subluxation, our one and only job is to locate and correct subluxations. Some even go so far as to refuse to refer a patient to an allopath, taking the position that they are not educated to know to whom one should refer, thus leaving it entirely to the discretion of the patient regarding whether or not to consult with another health-care provider.

At the other end of the spectrum is Alternative Medicine Integration, Inc. (AMI) which is located in Highland Park, Illinois. This organization has placed chiropractic physicians as gatekeepers in an HMO that is contracted with Blue Cross/Blue Shield of Illinois. We will hear more about this program from Dr. Richard Sarnat who was a co-founder of this program. The reality is that chiropractic practice can be integrated with allopathic practice in such a way as to fully meet this component of Primary Care-providing for integrated care for the patients.

\section{Addressing a Majority of Health Care Needs}

On its face, this seems to be problematic and it is, in reality, if one defines the practice of chiropractic as the correction of spinal "subluxations" for the purpose of improving health. There is simply no factual evidence to support this concept.

On the other hand, as has been demonstrated by AMI, broad-scope chiropractic physicians have a good record of diagnosing a majority of health care needs [Dr. Sarnat has reported that the chiropractic diagnoses agreed with the allopathic diagnoses in excess of $90 \%$ of the time (Sarnat R. Personal communication)], but can also manage the majority of health-care needs.

The key to success here is the ability of the chiropractic physician to bring a variety of therapeutic tools to bear on the health-care problems of the patient. The AMI experience clearly reveals that patients in the primarycare arena can be managed with about $50 \%$ less prescription drugs when other more conservative management procedures are utilized. These include, but are not limited to, articular manipulation, nutrition, supplementation, herbal medicine, homeopathic medicine, meridian therapy, exercise programs and others. All of these are within the realm of well-educated chiropractic physicians, but they are not part of the procedures used by those members of the profession who claim to be "subluxation based." On the contrary, those members and their leaders repeatedly have stated that procedures outside the adjustment of the spine are not within the realm of chiropractic practice.

These opposing positions mitigate against the practice of primary care by the profession at large and therefore represent one of the barriers that must be addressed and overcome if members of the chiropractic profession are to engage in primary care as it is generally defined. One of our tasks then, is to articulate a professional posture that would allow for those who are properly educated to practice primary care while others in the profession choose not to do so.

\section{Accessibility}

The chiropractic profession, like the allopathic profession, has congregated in those parts of the country which are perceived, for various reasons, to be "better places to live." Thus, we have a significant population of chiropractic doctors in all of the coastal areas and in and around major metropolitan communities.

Fortunately, because of the general nature of the development of the chiropractic profession the distribution in rural America is not as weak as one might expect it to be.

In a general sense, I believe that accessibility is not a significant issue, since our professional distribution, while not ideal, is reasonable and also because chiropractors have always been portal of entry providers.

\section{Sustained Partnership With Patients}

I believe it is generally accepted that chiropractic doctors relate well with their patients and they, in turn see their chiropractic physician as a valued advocate $(5,6)$. While this is true, it does not necessarily mean that the chiropractic physician is skilled in, nor oriented toward, sheparding a patient through a circumstance in which the patient needs the services of one or more specialists in a secondary or tertiary setting. In fact, most chiropractic doctors have little or no experience at the tertiary level of health care and this is an issue that must be addressed if a complete approach to primary care practice is anticipated.

It is my contention that a significant segment of the profession would not be suited to the role of partnering with a patient through a complex secondary and tertiary care circumstanced. This is particularly true of those in the profession who claim to be "subluxation based." They have neither the education, nor the inclination to serve in this capacity even though in some 
fragmented way they see themselves as patient advocates, with this most often happening in the personal injury cases.

\section{Practice Within The Context of Family and Community}

Here, the majority of practicing chiropractic doctors of today have little real experience from the primary care perspective. As a profession, we have spent a lot of time defending the profession and precious little time directed toward improving the general health of the members of society. The involvement by the chiropractic doctor in educating the patient in good nutrition, proper life-style, mechanisms for reducing the effects of negative stress etc., has been practiced almost exclusively by those in the profession who are broad scope oriented.

To many chiropractors, the idea of "practice within the context of family," means that they should find a way to get the whole family in for regular adjustments. Practice within the context of community means that the chiropractor joins some of the local service clubs so that the practice can be built.

Where we have, for the most part, been a dismal failure is in the context of bringing a voice of reason to the health-care concerns of the community as they relate to the quality of water, air, dwellings, workplace issues etc. Some within the profession have even been a negative influence by promoting anti-vaccination campaigns, anti-fluoridation campaigns etc. While I understand and appreciate the desire to support parental rights in these matters, too often chiropractic dogmatists have taken the position that vaccination, for example, is unnecessary if all the children simply receive regular adjustments. This kind of rhetoric does nothing to improve the health of the community in general unless, or until such time as we have some evidence for this kind of thinking.

\section{CONCLUSION}

While some of the members of the chiropractic profession have clearly demonstrated the ability and the value of chiropractic physicians functioning as primary-care providers in the United States, there remain some significant intraprofessional hurdles which are firmly grounded in professional dogma, and mitigate against the profession, as a whole taking a posture that it can provide primary care as it is generally understood. Specific difficulties relate to:

1. A lack of commitment to the need for competent diagnosis of patient health status among a significant but minority group within the profession.

2. A dogmatic adherence to untenable concepts of the cause and effect of health and disease in humans, by a significant minority of the profession.

3. An unhealthy desire on the part of a minority of chiropractic practitioners to denigrate allopathic medicine.

4. The continued intraprofessional division regarding scope of practice which generally is promoted by those who practice a narrow scope. Members of this ilk typically take the position that chiropractic is "correction of subluxation only" and anything else is not chiropractic.

5. Continued teaching by some chiropractic schools of theory that is unsupported by any scientific evidence.

6. A lack of understanding by some members of the profession regarding the context of primary-care practice as it is generally understood with an insistence on their part that chiropractic should define primary care as it sees fit.

7. A continued effort by some members of the profession to denounce generally accepted public health measures.

\section{REFERENCES}

1. Beideman RPB. In the making of a profession. Lombard, IL: National College of Chiropractic 1995. p. 139.

2. Palmer BJ. The science of chiropractic. Davenport, IA: Palmer College of Chiropractic 1906-1910. p. 171.

3. Howard JFA. Class notes included in The Encyclopedia of Chiropractic - the Howard System in 1912. Chicago, IL; National College of Chiropractic, 1910.

4. Koch DB. Streams From the Fountainhead. Fountainhead Spring 2002. p. 12-13.

5. Sawyer CE, Kassak K. Patient satisfaction with chiropractic care. J Manipulative Phsyiol Ther 1993;16:25-32.

6. Bemmell HA, Hayes BM. Patient satisfaction with chiropractic physicians in an independent physician's association. J Manipulative Physiol Ther 2001; 24:556-59. 